\title{
Role of Magnetic Resonance Imaging (MRI) in the Diagnosis of Pediatric Posterior Fossa Tumors
}

\author{
MAHA A.S. AHMED, M.Sc.; MAHMOUD A. DAWOUD, M.D.; HYTHAM H. EL-SAED, M.D. and \\ EHAB E. EL-GAMAL, M.D.
}

The Department of Radiodiagnosis, Faculty of Medicine, Tanta University, Tanta, Egypt

\begin{abstract}
Aim and Objectives: To assess role of MRI in evaluation of space occupying lesions seen at the posterior fossa in pediatric age group.

Methodology: This study included 20 patients in pediatric age group suspected to have posterior fossa tumors with neurological symptoms and CT findings, all pateints underwent MRI brain with contrast with diffusion weighted images and $\mathrm{ADC}$ values were obtained.
\end{abstract}

Results: A total of 20 patients underwent MRI were: 12 males $(60 \%)$ and 8 females $(40 \%)$ their ages ranged from 8 months, according to conventional MRI findings the most common pediatric posterior fossa tumor was medulloblastoma in 8 cases followed by Ependymoma in 4 cases and JPA in 4 cases while pontine glioma was found in 3 cases and one case of schwannoma, based on DWI and ADC map cut off values of $0.9 \times 10^{-3} \mathrm{~mm}^{2} / \mathrm{s}$ were specific for medulloblastoma while cut off values more than $1.4 \times 10^{-3} \mathrm{~mm}^{2} / \mathrm{s}$ were specific for JPA. In cases of glioma and Schwannoma showed free diffusion with ADC values higher than $1 \times 10^{-3} \mathrm{~mm}^{2} / \mathrm{s}$, cases of Ependymoma showed heterogeneous signal on DWI and ADC map with ADC value ranging from 1.01 and $1.3 \times 10^{-3} \mathrm{~mm}^{2} / \mathrm{s}$ suggesting restricted diffusion more than that seen in JPA cases. By comparing MRI findings with histopathology it was found that conventional MRI combined with DWI and ADC values show sensitivity $94 \%$ which is statistically significant positive strong correlation between MRI diagnosis and Histopathological confirmation.

Conclusion: Conventional MRI is the primary imaging modality used for the evaluation of posterior fossa tumors in pediatric age. Advance MRI (diffusion weighted images and ADC map) discriminates much better between different types of pediatric brain tumors. The study demonstrated that pilocytic astrocytomas (JPAs) are characterized by significantly higher ADC values than Ependymomas (EPs) and medulloblastomas, while medulloblastoma has the lowest ADC value, which seem to reliably provide the diagnosis which may affect the treatment plan and prognosis.

Key Words: MRI-Pediatric-Posteriorfossa tumors.

Correspondence to: Dr. Maha A.S. Ahmed, The Department of Radiodiagnosis, Faculty of Medicine, Tanta University, Tanta, Egypt

\section{Introduction}

INFRATENTORIAL intra axial masses that occur in the cerebellum or the brain stem are distinctly different in the pediatric and the adult population. Approximately $65 \%$ of all pediatric tumors arise in the posterior fossa. In children CT and MRI findings are used in combination with the location of the tumor as well as the patient age and sex may reliably predict tumor histology in more than $70 \%$ of cases [1].

Common posterior fossa brain tumor in children include pilocystic astrocytoma which is the most common pediatric cerebellar neoplasm and usually clinically benign [3], Medulloblastoma (MB), ependymoma and brain stem glioma, less commonly Atypical Rahbdoid Teratoid (ATRT), Hemangioblastome (HB), dermoid, schwannoma of the VIII cranial nerve, cerebellar gangliocytoma, meningioma, high grade glioma and metastatic lesion are encountered. Because these various tumors require very different treatment approaches and have significantly different natural histories and outcome, an accurate and specific diagnosis is mandatory [2]

Conventional MRI is essential for diagnosis as well as evaluation of location, quality and extent of the tumor and involved brain tissue (grey matter versus white matter), but often offer limited information about tumor grade and type. Additional more specific noninvasive diagnostic tests are needed. Recent studies evaluated the role of diffusion weighted imaging in differentiation grade and type of pediatric brain tumors in the posterior fossa [3].

Advanced MR neuroimaging technique allows assessment of the physical features of brain tumors, 
resulting in better preoperative characterization and often better outcome [4]. Measurements of the ADC expected to be useful in tumor assessment because variation in water content and diffusivity, which can be found in tumors for various reasons (e.g. vasogenic edema) likely provide information that is not readily available from conventional MR imaging [5].

\section{Patients and Methods}

This prospective study was conducted at Department of Radiology, Tanta University Hospital and Tanta University Educational International Hospital at the period between January 2016 and January 2017 and included 20 patients in pediatric age group suspected to have posterior fossa tumors with neurological symptoms and CT findings.

\section{The selection criteria were:}

Patients with suspicious of space occupying lesion at posterior fossa by neurological complain (headache, vomiting, visual complain, ataxia) or $\mathrm{CT}$ with space occupying lesion at posterior fossa.

\section{Exclusion criteria were:} MRI.

Patients who was contraindicated to perform

- Patients with intraocular metallic foreign body.

- Patients with MR non compatible intracranial clips of arterial brain aneurysms.

- Patient who refuse the examination.

- Patient with renal impairment.

All patients were subjected to the following:

- Informed consent obtained from all patients.

- Proper history taking:

I- Personal history: As regard name, age and sex.

II- Present history: As regard the presenting symptoms as headache, squint, tremors, blurred vision or numbness.

III- Past history: As regard any previous neurological diseases.

- General examination and vital signs.

- Neurological examination.

- Magnetic Resonance Imaging (MRI): MRI scans were performed using Toshiba Vantage Titan 1.5$\mathrm{T}$ scanner closed magnet and GE Signa Explorer 1.5-T closed magnet using a head coil at MRI unit, Radiology department, Tanta University
Hospital. The slice thickness was $6 \mathrm{~mm}$, the matrix was 256 X 256 and the field of view was 220$240 \mathrm{~mm}$.

\section{Patient preparation:}

First patient was asked about any contraindication to MRI and instructed to remove metallic object, the procedure is explained for reassurance, patient were informed about the duration of examination and value of remaining motionless.

Five patients were sedated using Chloral Hydrate $0.5 \mathrm{ml} / \mathrm{kg}$ just before the examination. Patient positioning.

All patients were examined supine with the use of standard head coil and immobilized in comfortable position.

\section{Pulse sequence and scanning plane:}

- A scout T1 weighted sagittal image view to verify precise position of patient and act as a localizer of subsequent slices.

- Multiple pulse sequences in all three orthogonal planes were used to obtain axial images followed by coronal and sagittal images.

- Diffusion weighted imaging with apparent diffusion coefficient calculation:

DW images were obtained by using an axial echo-planar SE sequence, average, $5 \mathrm{~mm}$ section thickness. DW images and ADC maps were acquired by using $b$ values of 0 and $1000 \mathrm{~s} / \mathrm{mm}^{2}$. Post processing of ADC maps was performed. Standard mean ADC values werre cąlculated automatically and expressed in $10^{-3} \mathrm{~mm} / \mathrm{s}$.

- The diagnosis was confirmed histopathologically by open biopsy.

Statistical analysis was carried out using SPSS software and the following were used:

- Range and mean value \pm standard deviation.

- Chi-square.

- Montecarlotest.

- Correlation of the parameters with each other.

$p$-value $<0.05$ is considered statistically significant, $p$-value $<0.001$ is considered highly significant.

\section{Results}

Among 20 patients included in this study 12 males $(60 \%)$ and 8 females (40\%) their ages ranged from 8 months to 15 years (Table 1 ). 
Table (1): Distribution of patient characteristics according to MRI diagnosis.

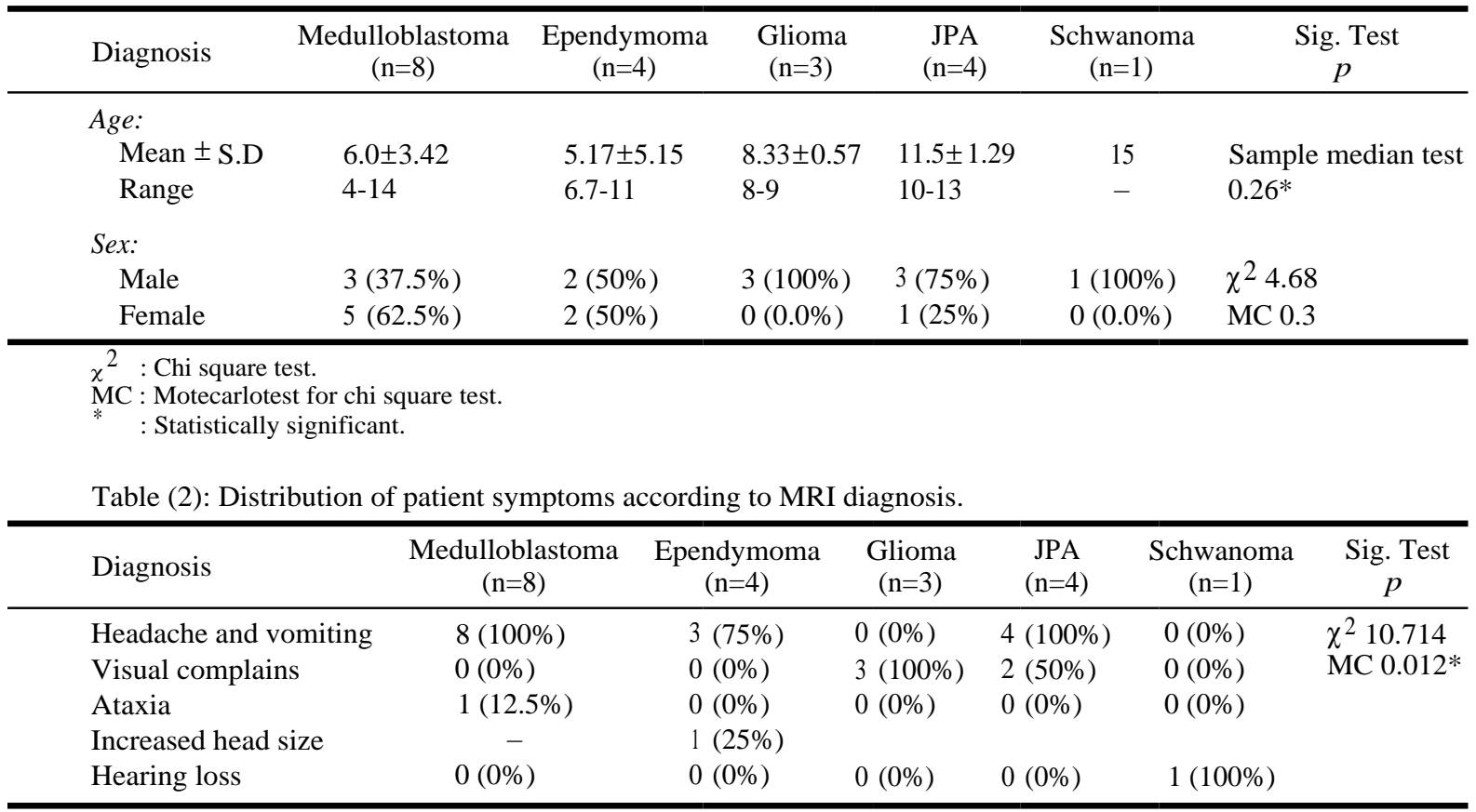

$\chi^{2}:$ Chi square test.

MC : Motecarlotest for chi square test.

: Statistically significant.

Table (3): MRI diagnosis in the study patients.

\begin{tabular}{lll}
\hline Diagnosis & $\mathrm{N}$ & $\%$ \\
\hline Medulloblastoma & 8 & 40 \\
Ependymoma & 4 & 20 \\
JPA & 4 & 20 \\
Glioma & 3 & 15 \\
Schwannoma & 1 & 5 \\
\hline Total & 20 & 100.0 \\
\hline
\end{tabular}

Table (4): Distribution of other MRI findings according to MRI diagnosis.

\begin{tabular}{lcccccc}
\hline Diagnosis & $\begin{array}{c}\text { Medulloblastoma } \\
(\mathrm{n}=8)\end{array}$ & $\begin{array}{c}\text { Ependymoma } \\
(\mathrm{n}=4)\end{array}$ & $\begin{array}{c}\text { Glioma } \\
(\mathrm{n}=3)\end{array}$ & $\begin{array}{c}\text { JPA } \\
(\mathrm{n}=4)\end{array}$ & $\begin{array}{c}\text { Schwanoma } \\
(\mathrm{n}=1)\end{array}$ & $\begin{array}{c}\text { Sig. Test } \\
p\end{array}$ \\
\hline Necrosis & $1(12.5 \%)$ & $1(25 \%)$ & $1(33.3 \%)$ & & $\chi^{2} 10.79$ \\
Hemorrhage & $3(37.5 \%)$ & & $1(33.3 \%)$ & & MC $0.017^{*}$ \\
Cystic changes & $1(12.5 \%)$ & $1(25 \%)$ & $1(33.3 \%)$ & $4(100 \%)$ & & \\
Hydrocephalus & $5(62.5 \%)$ & $3(75 \%)$ & $1(33.3 \%)$ & $2(50 \%)$ & - & \\
\hline
\end{tabular}

$\chi^{2}:$ Chi square test.

MC : Motecarlotest for chi square test.

: Statistically significant.

Table (5): DWI and ADC map in different MRI diagnosis.

\begin{tabular}{|c|c|c|c|c|c|c|}
\hline Diagnosis & $\begin{array}{l}\text { Medulloblastoma } \\
\qquad(\mathrm{n}=8)\end{array}$ & $\begin{array}{c}\text { Ependymoma } \\
(n=4)\end{array}$ & $\begin{array}{c}\text { Glioma } \\
(\mathrm{n}=3)\end{array}$ & $\begin{array}{c}\text { JPA } \\
(n=4)\end{array}$ & $\begin{array}{l}\text { Schwanoma } \\
(\mathrm{n}=1)\end{array}$ & $\begin{array}{l}\text { Sig. Test } \\
p\end{array}$ \\
\hline $\begin{array}{l}D W I: \\
\quad \text { Restricted } \\
\quad \text { Free }\end{array}$ & $8(100 \%)$ & $4(100 \%)$ & $\begin{array}{l}1(33.3 \%) \\
2(66.7 \%)\end{array}$ & $4(100 \%)$ & $1(100 \%)$ & $\begin{array}{l}\chi^{2} 10.179 \\
\text { MC } 0.014 *\end{array}$ \\
\hline $\begin{array}{l}\text { ADC map: } \\
\quad \text { Mean } \pm \text { S.D }\end{array}$ & $0.75 \pm 0.46$ & $1.00 \pm 0.0$ & $1.33 \pm 0.58$ & $1.75 \pm 0.5$ & 1.0 & $\begin{array}{l}\text { F } 18.73 \\
p 0.001 *\end{array}$ \\
\hline
\end{tabular}


Table (6): MRI diagnosis versus histopathological diagnosis.

\begin{tabular}{|c|c|c|c|c|c|c|}
\hline & \multicolumn{5}{|c|}{ MRI diagnosis } & \multirow{2}{*}{$\begin{array}{l}\text { Sig. Test } \\
\quad \& p\end{array}$} \\
\hline & $\begin{array}{l}\text { Medulloblastoma } \\
\qquad(\mathrm{n}=8)\end{array}$ & $\begin{array}{l}\text { Ependymoma } \\
\qquad(\mathrm{n}=4)\end{array}$ & $\begin{array}{c}\text { Glioma } \\
(\mathrm{n}=3)\end{array}$ & $\begin{array}{c}\text { JPA } \\
(\mathrm{n}=4)\end{array}$ & $\begin{array}{l}\text { Schwanoma } \\
\quad(\mathrm{n}=1)\end{array}$ & \\
\hline Histo-pathological & $8(100 \%)$ & $\begin{array}{l}\text { Ependymoma } \\
4(100 \%)\end{array}$ & - & $\begin{array}{l}3(75 \%) \mathrm{JPA} \\
1(25 \%) \\
\text { hemangioblastoma }\end{array}$ & $1(100 \%)$ & $\begin{array}{l}x^{2} 34.0 \\
\text { MC } 0.001 *\end{array}$ \\
\hline
\end{tabular}

Table (7): Correlation between MRI diagnosis and Histopathological diagnosis.

\begin{tabular}{llc}
\hline & \multicolumn{2}{c}{ MRI diagnosis } \\
\cline { 2 - 3 } & $r$ & $p$ \\
\hline Histo-pathological & $0.914^{*}$ & $0.001^{*}$ \\
\hline & : Correlation by spearman rank corelation. \\
& : Statistically significant.
\end{tabular}

Statistically significant positive strong correlation between MRI diagnosis and histopathological confirmation.

Table (8): Sensitivity of MRI in detection of posterior fossa tumors in comparison to histopathological diagnosis "the gold standard".

\begin{tabular}{lcccc}
\hline & \multicolumn{2}{l}{ Histo-pathological diagnosis } & Sensitivity \\
\cline { 2 - 4 } & Positive & Negative & Total & $\%$ \\
\hline $\begin{array}{c}\text { MRI diagnosis: } \\
\text { Positive }\end{array}$ & 16 & 0 & 16 & $94.1 \%$ \\
Negative & 1 & 0 & 1 & \\
\hline Total & 17 & 0 & 17 & \\
\hline
\end{tabular}

MRI was true positive for 16 cases confirmed by histopatholgical correlation, one case was corrected by another diagnosis in histopathology, while histopathology from 3 cases were not available because of inoperable tumor and death of patients.

\section{Discussion}

Conventional, anatomical MRI is an essential tool for diagnosis and evaluation of location, quality, and extent of posterior fossa tumors, but offers limited information regarding tumor grade and type. Advanced MRI techniques such as Diffusion Weighted Imaging (DWI) may improve the specific diagnosis of brain tumors in the posterior fossa in children [6]. DW imaging has been applied for the assessment of tumor grades or differentiation of tumor types, as well as for the diagnosis of other brain SOLs. Recent studies evaluated the role of Diffusion Weighted Imaging (DWI) in differentiating grade and type of pediatric brain tumors in the posterior fossa [7]. Diffusion MR imaging is a technique which allow evaluation of microscopic water diffusion within tissues, where calculated ADC maps represent an absolute measure of average diffusion for each voxel [8]. In the current study 20 patients were examined in radiodiagnosis department, Tanta University after neurological examination. Patients were studied by conventional MRI and diffusion study and the results were compared by histopathological examination in 17 cases by open biopsy while 3 cases died and diagnosis depended only on clinical picture, MRI findings and outcome of the disease. This study was encountered on 20 patients, 12 males $(60 \%)$ and 8 females (40\%), this was in agreement with Wrench, et al., [9] in their study as they found that the incidence of pediatric brain tumors among males was more than females. Most of cases diagnosed as medulloblastoma were younger than 16 years, this agree with Verna, et al., [10] as they found that medulloblastoma is the most frequent malignant with peak incidence between 3 and 9 years, in this study 5 cases of medulloblastoma were females opposite to 3 males only diagnosed as medulloblastoma this disagree with Poretti, et al., [11] who found medulloblastoma is twice as common in boys as in girls, while in pilocytic astrocytoma their age ranges from 9 to 14 years old this agree with Docampo, et al., [12] as they found peak incidence of pilocytic astrocytoma between 5-13 years and occur equal in both males and females, cases diagnosed as ependymoma their age from 8 months to 6 years this agree with Prince, et al., [13] who found that the mean age of diagnosis was from 5-6 years and $20-40 \%$ of cases occur in children younger than 2 years. According to conventional MRI findings, the most common pediatric posterior fossa tumors encountered in our study were medulloblastoma (8 cases), pilocytic astrocytoma in ( 4 cases), ependymoma in (4 cases), diffuse pontine glioma in (3 cases) and Schwannoma only in (1 case) this disagree with Cascone, et al. [14] who reported juvenile pilocytic astrocytoma as the most frequent posterior fossa tumor in children accounts for $30-35 \%$ of cases. As regards site, 
all cases of pilocytic astrocytoma were seen located near mid line arising from cerebellum as wellcircumscribed, cystic like masses with a soft tissue mural nodule this agree with Kelly, et al., [15], while in medulloblastoma 5 cases were located at cerebellar vermis and three cases located at cerebellar hemisphere this agree with FruehwaldPallamar J., et al. [16] as they concluded $75 \%$ of cases of medulloblastoma occur at cerebellar vermis and tend to protrude through fourth ventricle while adult medulloblastoma usually located laterally in the cerebellar hemisphere only $28 \%$ centered in the vermis, in cases of glioma all cases were of diffuse pontine glioma group this agree with Donaldson, et al. [17] as they reported diffuse pontine glioma accounts for $60-75 \%$ of all posterior fossa glioma.

In the studied cases the most common other MRI association was hydrocephalus present in 11 cases 5 of them were medlloblastoma (55\%), the other findings were cystic changes present in 7 cases 4 of them were juvenile pilocytic astrocytoma cases $(35 \%)$ and hemorrhage present in 4 cases 3 of them were medulloblastoma (20\%), this agree with Reddy, et al., [18] who reported hydrocephalus as the most common association especially in midline tumor as they obstruct fourth ventricle. In the studied cases as regard the pattern of enhancement after gadolinium injection in group I (medulloblastoma) 6 cases show heterogeneous enhancement while 2 cases show homogenous enhancement this agree with Eran, et al., [19], In group II (Ependymoma) the four cases show heterogeneous enhancement, in group III (JPA) all solid nodules show homogemous enhancement and in group IV (pontine glioma) one case show heterogeneous enhancement one case show faint enhancement and one show no enhancement, while in case of schwannoma show homogenous intense enhancement this agree with Mauffrey [6] who found in case of ependymoma $50 \%$ of cases showed heterogeneous enhancement that may indicate calcification, necrosis, hemosiderin, or tumor vascularity while in cases of glioma as regads Gadolinium enhancement can be variable, but mostly these tumors show no or only minimal contrast enhancement. As regards diffusion weighted imaging and ADC maps JPA and medulloblastoma could be differentiated on the basis of ADC value in all patients and there was no overlap in the obtained measurements between the two tumor types. 2 The ADC value was higher than $1.3 \times 10^{-3} \mathrm{~mm} / \mathrm{s}$ in JPA cases while in medulloblastoma cases the ADC values ranged between 0.55 and $0.9 \times 10^{-3} \mathrm{~mm} / \mathrm{s}$, indicating a statistically significant difference in the ADC values between the two tumor types, in consistent with Rumboldt et al., [21], as they concluded that significant differences in cellularity of pediatric cerebellar neoplasms, particularly between JPAs and medulloblastomas indicate that these lesions could potentially be distinguished by their ADC yalueş, used cut off values of more than 1.4 $\times 10^{-3} \mathrm{~mm} / \mathrm{s}$ for JPA and less than $0.9 \times 10^{-3}$ $\mathrm{mm}^{2} / \mathrm{s}$ for medulloblastoma which seem to reliably provide the diagnosis which may affect the treatment plan and prognosis. In studied cases of ependymoma all cases show heterogeneous signal in DWI and ADC map with $\mathrm{ADC}$ value ranging from 1.01 and $1.3 \times 10^{-3} \mathrm{~mm}^{2} / \mathrm{s}$ suggesting restricted diffusion more than that seen in JPA cases consistent with Yamasaki et al., [22] as they found that ADC values were retrospectively $100 \%$ accurate in the differentiation between ependymomas and medulloblastomas as Ependymomas are well circumscribed, moderately cellular tumors. The typical cellularity in posterior fossa ependymomas therefore is somewhere between that of astrocytomas and medulloblastomas. In the studied cases of diffuse brain stem Glioma cases the signal intensity was hypointense on DWI compared to normal brain parenchyma denoting free diffusion, some cases show heterogeneous signal intensity in DWI and ADC map denoting high grade of anaplasia with $\mathrm{ADC}$ value ranging from $1.1 \times 10^{-3}$ to $1.5 \times 10^{-3}$ consistent with Lobel, et al. [23]. In case of Schwannoma the signal intensity was hypointense on DWI and hyperintense on ADC map compared to normal parenchyma denoting free diffusion it had ADC value of $1.6 \times 10^{-3}$ consistent with Beaman FD et al., [24]. Based on these results, ADC values may play a potentially important role in the pre-operative management of children with posterior fossa tumors. If high ADC value is detected, a patient may go directly to surgery as pilocytic astrocytoma is unlikely to metastasize via CSF seedling. On the other hand, very low ADC value suggests that the tumor is medulloblastoma, so imaging of the spine is essential to exclude metastases. By comparing MRI findings with histopathology it was found that conventional MRI combined with DWI and ADC values show sensitivity $94 \%$ which is statistically significant positive strong correlation between MRI diagnosis and histopathological confirmation.

\section{Conclusion:}

From the current study it can be concluded that conventional MRI is the primary imaging modality used for the evaluation of posterior fossa tumors in pediatric age. Advance MRI (diffusion weighted images and ADC map) discriminates much better between different types of pediatric brain tumors. 
The study demonstrated that pilocytic astrocytomas (JPAs) are characterized by significantly higher ADC values than Ependymomas (EPs) and medulloblastomas, while medulloblastoma has the lowest ADC value, which seem to reliably provide the diagnosis which may affect the treatment plan and prognosis.

\section{References}

1- PLAZA M., BORJA M., ALTMAN N., et al.: Conventional and advanced MRI features of pediatric intracranial tumors. American Journal of Roentgenology, 200: 111524, 2013.

2- CHOURMOUZI D., PAPADOPOULOU E., KONSTAANTINIDIS M., et al.: Manifestation of Pilocytic astrocytoma: A pictorial view. Insights Imaging, 5: 384402, 2014.

3- WALID M.S. and TROUP E.C.: Cerebellar anaplastic astrocytoma in teenager with Ollier disease. Journal of Nuero-Oncology, 89: 59-62, 2009.

4- DREVELEGAS A.: Imaging modality in brain tumor. In: Imaging of brain tumor with histological correlations. Edited by Drevelegas. 2 nd ed. New York: Springer-Verlage A.13-33, 2001.

5- FAWZY F., AZEEM A., EL-HADY W., et al.: The role of apparent diffusion coefficient (ADC) value in the differentiation between the most common pediatric posterior fossa tumors. The Egyptian Journal of Radiology and Nuclear Medicine, 44: 349-59, 2013.

6- PROVENZALE J.M., MUKUNDAN S., BARBORIAK D.P., et al.: Diffusion weighted and perfusion MR imaging for brain tumor characterization and assessment of treatment response. International society of magnetic resonance imaging in Medicine, 239: 632-49, 2006.

7- HUMPHRIES P.D., SEBIRE N.J., SIEGEL M.J., et al.: Tumors in pediatric patients and diffusion weighted MR imaging: Apparent diffusion coefficient and tumor cellularity. Radiology, 245: 848-54, 2007.

8- SCHNEIDER J.F., CONFORT-GOUNY S., VIOLA A., et al.: Multiparametric differentiaition of posterior fossa tumor in children using Diffusion-weighted imaging and short Echo-Time 1 H-MR spectroscopy. Journal of Magnetic Resonance Imaging, 26: 1390-8, 2007.

9- WRENSCH M., MINN Y., CHEW T., et al.: Epidemiology of primary brain tumors: Current concepts and review of literature. Neuro Oncology, 4: 278-99, 2002.

10- VERMA J., MAZLOOM A., TEH B.S., et al.: Comparison of supine and prone craniospinal irradiation in children with medulloblastoma. Practical Radiation Oncology, 5: 93-8, 2014.
11- PORETTI A., MEODED A. and THIERRY A.G.: Neuroimaging of pediatric posterior fossa tumor including the review of the literature. Journal of Magnetic Resonance Imaging, 35: 32-47, 2011.

12- DOCAMPO J.D., GONZALEZ N., BRUNO C., et al.: Pilocytic astrocytoma typical and atypical CT and MRI imaging findings. European Society of Radiology, 569: 1-37, 2012.

13- PRINCE M.R. and CHEW F.S. : Ependymoma of the fourth ventricle. American Journal of Roentgenology, 157: 1278-82, 1991.

14- CASCONE D., PANICO M., CICALA D., et al.: neuroimaging of posterior fossa astrocytoma in children. American Journal of Roentgenology, 3 54: 3 19-25, 2015.

15- KELLY K., KOELLER, ELISABETH J., et al.: From the archives of the AFIP. Pilocytic Astrocytoma: Radiologicpathologic correlation. Radiographics, 24: 1693-708, 2004.

16-FRUEHWALD-PALLAMAR J., PALLAMAR S.B., ROSSI A., et al.: Magentic resonance imaging spectrum of medulloblastoma. Neuroradiology, 53: 387-96, 2011.

17- DONALDSON S., LANINGHAM F. and FISHER P.G.: Advances towards understanding brain stem gliomas. Journal of Clinical Oncology, 24: 1266-72, 2006.

18- REDDY G., LAM S., LIN Y., et al.: Mangement of hydrocephalus in children with posterior fossa tumor. Surgical Neurology International, 6: 346-8, 2015.

19- ERAN A., OZTURK A., AYGUN N., et al.: Medulloblastoma: Atypical CT and MRI findings in children, Pediatric Radiology Journal, 40: 1254-62, 2010.

20- MAUFFREY C.: Pediatric brain stem gliomas: Prognostic factors and management. Journal of Clinical Neuroscience, 13: 431-7, 2006.

21- RUMBOLDT Z., CAMACHO D., LAKE D., et al.: Apparent diffusion coefficients for differnation of cerebellar tumors in children. American Journal of Neuroradiology, 27: 1362-9, 2006.

22- YAMASAKI F., KURISU K., SATOH K., et al.: Apparent diffusion coefficient of human brain tumors at MR imaging, Radiology, 235: 985-91, 2005.

23- LOBEL U., SEDLACIK J., REDDICK W.E., et al.: Quantitaive diffusion weighted and dynamic susceptibility weighted contrast enhanced perfusion MR imaging analysis of $\mathrm{T} 2$ hypointense lesion components in pediatric diffuse intrinsic glioma, American Journal of Neuroradiology, 32: 315-22, 2011.

24- BEAMAN F., KRANSDORF M. and MENKE D.: Schwannoma: Radiologic-pathologic correlation. Radiographics, 24: 1477-81, 2011. 


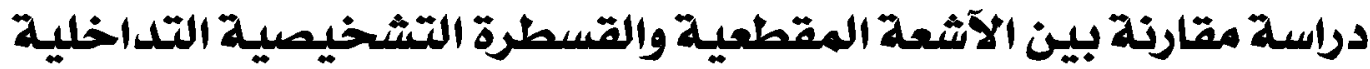

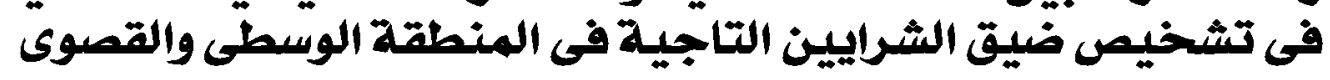

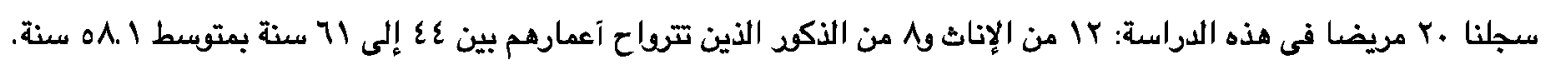
والهدف من هذه الدراسة هو تقييم دقة الآشعة المقطعية لتصوير الشرايين التاجية للكشف عن ضيق الشريان التاجى بإستخدام تصبوير الأوعية التاجية التداخلية كمعيار مرجعى.

يثشنى من الدراسة المرضى الذين سبق لهم تركيب دعامات بالآوعية التاجية آو سبق لهم عمل جراحة قلب مفتوح للآوعية التاجية، ويشتنى آيضا مرضى قصىو الكلى آى الحوامل.

الإستتاج: تصوير الآوعية التاجية بواسطة الآثعة المقطعية هو آداة موثوقة وذات دقة عالية اللكشف عن ضيق الشترايين التاجية في كل

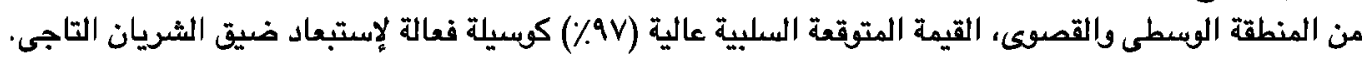

